\title{
Binet Stage B
}

National Cancer Institute

\section{Source}

National Cancer Institute. Binet Stage B. NCI Thesaurus. Code C80135.

Patients have no anemia or thrombocytopenia and three or more areas of lymphoid involvement. 